\title{
Avaliação da utilização ácidos orgânicos sobre a qualidade físico-química e microbiológica da cama de aviário
}

\author{
Evaluation of the use of organic acids on the physicochemical and microbiological quality of \\ poultry litter
}

Evaluación del uso de ácidos orgánicos en la calidad físico-química y microbiológica de la cama de las aves de corral

Edemar Aniecevski ORCID: https://orcid.org/0000-0001-6095-7187 Universidade do Oeste de Santa Catarina, Brasil E-mail: edemar3004@gmail.com

Gabriela Miotto Galli

ORCID: https://orcid.org/0000-0001-6734-8659 Universidade Federal do Rio Grande do Sul, Brasil E-mail: gabi-gmg@hotmail.com

Heloísa Pagnussatt

ORCID: https://orcid.org/0000-0002-0139-9872 Universidade do Oeste de Santa Catarina, Brasil E-mail: heloisa_pagnussatt@ hotmail.com

Fernanda Danieli Antoniazzi Valentini ORCID: https://orcid.org/0000-0002-2868-8498 Universidade do Oeste de Santa Catarina, Brasil E-mail: Fernanda_antoniazzi@hotmail.com

Felipe Leite

ORCID: https://orcid.org/0000-0002-7834-4247 Universidade do Oeste de Santa Catarina, Brasil E-mail: leite.felipe00@gmail.com

Alícia Dal Santo

ORCID: https://orcid.org/0000-0002-9519-4033 Universidade do Oeste de Santa Catarina, Brasil E-mail: alicia.ds2411@gmail.com

Tiago Goulart Petrolli

ORCID: https://orcid.org/0000-0002-6175-5939 Universidade do Oeste de Santa Catarina, Brasil E-mail: tiago.petrolli@unoesc.edu.br

\begin{abstract}
Resumo
Objetivou-se na presente pesquisa avaliar o efeito da adição de um blend de ácidos orgânicos, seus sais e derivados de lignina na contagem bacteriana total da cama, bem como, na qualidade da mesma por meio de medições de $\mathrm{pH}$, atividade de água e teor de umidade. A pesquisa foi conduzida em três aviários comerciais, com área de $480 \mathrm{~m} 2$ cada, com a mesma data de alojamento das aves. Cada aviário recebeu uma dosagem, sendo estas de: 40,80 e $120 \mathrm{~g} / \mathrm{m}^{2}, 48$ horas antes do alojamento das aves, por toda a extensão do aviário. A coleta das amostras para análise (microbiológica, $\mathrm{pH}$, atividade de água e umidade) foi realizada em oito pontos em cada galpão em distintos períodos temporais. Constatou-se uma redução na contagem microbiana total seis horas após a aplicação do blend nas três dosagens avaliadas $(\mathrm{P}<0,001)$. Já aos 14 dias de criação do lote, observou-se menor contagem microbiana na cama tratada com $120 \mathrm{~g} / \mathrm{m} 2$ do blend, isto indica que esta dosagem pode retardar o crescimento microbiano ao longo do período de criação $(\mathrm{P}<0,001)$. No entanto, a partir dos 28 dias, a adição do blend em todas as dosagens testadas, não foi suficiente para retardar o crescimento microbiano $(\mathrm{P}>0.05)$. Os parâmetros de $\mathrm{pH}$, atividade de água e umidade não sofreram influência dos aditivos aplicados sobre a cama $(\mathrm{P}>0.05)$. Conclui-se que os ácidos e ligninas adicionados sobre a cama dos aviários, durante o intervalo entre lotes, possuem efeito mitigador da proliferação microbiana até aos 14 dias de alojamento.
\end{abstract}

Palavras-chave: Avicultura; Biosseguridade; Qualidade da cama.

\section{Abstract}

The objective of this study was to evaluate the effect of adding a blend of organic acids, their salts, and lignin derivatives on the total bacterial count of the litter, as well as on its quality through measurements of $\mathrm{pH}$, water 
activity, and moisture content. The research was conducted in three commercial poultry houses, with an area of $480 \mathrm{~m} 2$ each, with the same housing date of the birds. Each poultry house received a different dosage, of 40, 80, and $120 \mathrm{~g} / \mathrm{m}^{2}, 48$ hours before the accommodation of the birds, throughout the extension of the aviary. The collection of samples for analysis (microbiological, $\mathrm{pH}$, water activity, and humidity) was performed in eight points in each house in different periods. A reduction in the total microbial count was observed six hours after the application of the blend in the three dosages evaluated $(\mathrm{P}<0.001)$. At 14 days of rearing, lower microbial counts were observed in the litter treated with $120 \mathrm{~g} / \mathrm{m} 2$ of the blend, indicating that this dosage can slow microbial growth throughout the rearing period $(\mathrm{P}<0.001)$. However, after 28 days, the addition of the blend in all dosages tested was not sufficient to slow microbial growth $(\mathrm{P}>0.05)$. The parameters $\mathrm{pH}$, water activity, and moisture were not influenced by the additives applied on the bed $(\mathrm{P}>0.05)$. It is concluded that the acids and lignins added to the poultry litter, during the interval between flocks, have a mitigating effect on microbial proliferation until 14 days of housing.

Keywords: Biosecurity; Litter quality; Poultry.

\section{Resumen}

El objetivo del presente estudio era evaluar el efecto de la adición de una mezcla de ácidos orgánicos, sus sales y derivados de la lignina sobre el recuento total de bacterias de la cama, así como sobre su calidad mediante mediciones del $\mathrm{pH}$, la actividad del agua y el contenido de humedad. La investigación se llevó a cabo en tres gallineros comerciales, con una superficie de 480m 2 cada uno, con la misma fecha de alojamiento de las aves. Cada aviario recibió una dosis de: 40, 80 y $120 \mathrm{~g} / \mathrm{m}^{2}$, 48 horas antes del alojamiento de las aves, en toda la extensión de la pajarera. La recogida de muestras para el análisis (microbiológico, de pH, de actividad del agua y de humedad) se realizó en ocho puntos de cada nave en diferentes periodos de tiempo. Se observó una reducción del recuento microbiano total seis horas después de la aplicación de la mezcla en las tres dosis evaluadas $(\mathrm{P}<0,001)$. A los 14 días de cría, se observaron recuentos microbianos más bajos en la yacija tratada con $120 \mathrm{~g} / \mathrm{m} 2$ de la mezcla, lo que indica que esta dosis puede retrasar el crecimiento microbiano durante todo el periodo de cría $(\mathrm{P}<0,001)$. Sin embargo, después de 28 días, la adición de la mezcla en todas las dosis probadas no fue suficiente para frenar el crecimiento microbiano $(\mathrm{P}>0,05)$. Los parámetros de $\mathrm{pH}$, actividad del agua y humedad no se vieron influidos por los aditivos aplicados a la cama $(\mathrm{P}>0,05)$. Se puede concluir que los ácidos y las ligninas añadidos a la cama de las aves de corral durante el intervalo entre lotes tienen un efecto mitigador de la proliferación microbiana hasta los 14 días de alojamiento.

Palabras clave: Calidad de la camada; La bioseguridad; Pollos.

\section{Introdução}

No ano de 2020 o Brasil produziu 13,845 milhões de toneladas de carne de frango e um consumo interno de 45,27 $\mathrm{kg} / \mathrm{hab}$ (ABPA, 2021). O Brasil é o maior exportador de carne de frango do mundo, como também, um dos maiores produtores. No entanto, o local de criação das aves favorece a multiplicação de bactérias indesejáveis, e entre estes organismos principalmente, as bactérias do gênero Salmonella spp, que implicam em problemas inerentes à segurança dos alimentos, causam a condenação de carcaças e outros sérios problemas ligados a saúde pública (Dai Prá et al., 2009). Outras bactérias oportunistas, como Clostridium perfringens, Staphylococcus aureus e Escherichia coli, também estão no ambiente do aviário, e causam danos na produtividade dos lotes e problemas de contaminações.

A cama de aviário constitui um ótimo nicho para a multiplicação de bactérias, no qual apresenta em média de $14 \%$ de proteína bruta, $16 \%$ de fibra bruta, $13 \%$ de matéria mineral e $0,41 \%$ de extrato etéreo, e seu pH varia entre 6 e 9 (Fiorentin et al., 2005), com atividade de água (Aw) que atinge facilmente os índices de 0,90 (Dai Prá et al., 2009) e temperaturas entre 20 a $32^{\circ} \mathrm{C}$, conforme idade das aves. Todas estas condições compreendem um ambiente ideal para a multiplicação da Salmonella spp e de outros agentes patogênicos na cama (Heitmann et al., 2020). No século XXI uma prática comum na avicultura é a reutilização de camas entre lotes, o que torna ainda mais importante a implementação de alternativas para diminuir a carga bacteriana desse material (Galli et al., 2021).

Assim, as indústrias tem buscado alternativas para o controle microbiológico da cama de frangos de corte. Desta forma, existem vários métodos disponíveis para a redução da concentração de bactérias na cama, entre lotes, como o enleiramento e a fermentação da cama, porém, estes manejos isolados não são mais eficientes. Dentre as alternativas encontram-se os ácidos orgânicos de cadeia curta e seus sais, cujo mecanismo de ação está na habilidade de cruzar a membrana bacteriana, até o citoplasma, dissociando prótons e ânions orgânicos, interferindo no pH e homeostase da célula bacteriana, o 
que inclui modificações na estrutura da membrana, osmolaridade e síntese de macromoléculas (Polycarpo et al., 2017). Neste contexto, podemos destacar o ácido fórmico e o ácido propiônico, isolados ou em combinação, são potentes agentes antimicrobianos por meio das propriedades relatadas acima (Ma et al., 2021; Dai et al., 2021). Adicionalmente, derivados de lignina também possuem ação antimicrobiana (Bogusławska-Tryk et al., 2015) e reduzem a emissão de amônia (Röhe et al., 2020), podendo agir como redutor da atividade de água da cama, reduzindo o teor de umidade disponível para que haja desenvolvimento microbiano. Diante do exposto, objetivou se avaliar o efeito da adição de blend de ácidos orgânicos e seus sais e derivados de lignina na contagem bacteriana total da cama, bem como, na qualidade da mesma por meio de medições de $\mathrm{pH}$, atividade de água e teor de umidade.

\section{Metodologia}

\subsection{Delineamento experimental}

A presente pesquisa foi conduzida em três aviários comerciais com área de $480 \mathrm{~m}^{2}$ cada, com a mesma data de alojamento das aves localizados no Oeste de Santa Catarina, Brasil. Os ácidos e ligninas foram adicionados nas camas dos aviários nas dosagens descritas na Tabela 1, ou seja, cada aviário foi aplicado uma dosagem. O blend de ácidos orgânicos utilizado era composto por ácido fórmico ( $297 \mathrm{~g} / \mathrm{kg}$ do blend), ácido propiônico (57g/kg do blend), lignosulfato de sódio ( $75 \mathrm{~g} / \mathrm{kg}$ do blend) e veículo (571 $\mathrm{g} / \mathrm{kg}$ do blend). Os animais foram criados de acordo com as normas e manejos das granjas comerciais e do manual de linhagem (Cobb, 2019).

Tabela 1 - Dosagens dos ácidos orgânicos e ligninas aplicados na cama de três aviários.

\begin{tabular}{ll}
\hline Tratamento & Adição do blend na cama \\
\hline T40 & $40 \mathrm{~g} / \mathrm{m}^{2}$ de cama \\
T80 & $80 \mathrm{~g} / \mathrm{m}^{2}$ de cama \\
T120 & $120 \mathrm{~g} / \mathrm{m}^{2}$ de cama \\
\hline
\end{tabular}

Fonte: Autores.

\subsection{Manejo e coleta da cama}

Os aviários utilizados na presente pesquisa eram do tipo convencional e a cama reutilizada há cinco lotes. Desta forma, foram efetuadas aplicações do blend nas dosagens de 40, 80 e $120 \mathrm{~g} / \mathrm{m}^{2}$, na cama dos aviários durante o período de intervalo entre lotes, 48 horas anterior ao alojamento das aves, por meio do auxílio de um atomizador costal (Modelo Guarany 18L, Itu, SP, Brasil), por toda a extensão da cama de cada aviário, para garantir uma cobertura uniforme na superfície da cama. Para a coleta das amostras para análise (microbiológica, $\mathrm{pH}$, atividade de água e umidade) foi seguido o padrão de pontos de coleta descritos na Figura 1, sendo oito pontos de coleta dentro de cada aviário. Deste modo, para calcular a distância entre cada ponto, foi dividido o comprimento total de cada galpão por oito, para que as coletas fossem efetuadas de forma distribuída e equidistantes por toda a extensão do aviário.

A coleta das amostras foi efetuada em vários períodos temporais, sendo: antes da aplicação do produto (hora zero), seis horas após a primeira aplicação e posteriormente a cada sete dias, com a última coleta sendo efetuada aos 42 dias, ou seja, ao final do período experimental. 
Figura 1. Croqui esquemático das coletas de amostras ao longo da extensão dos aviários.

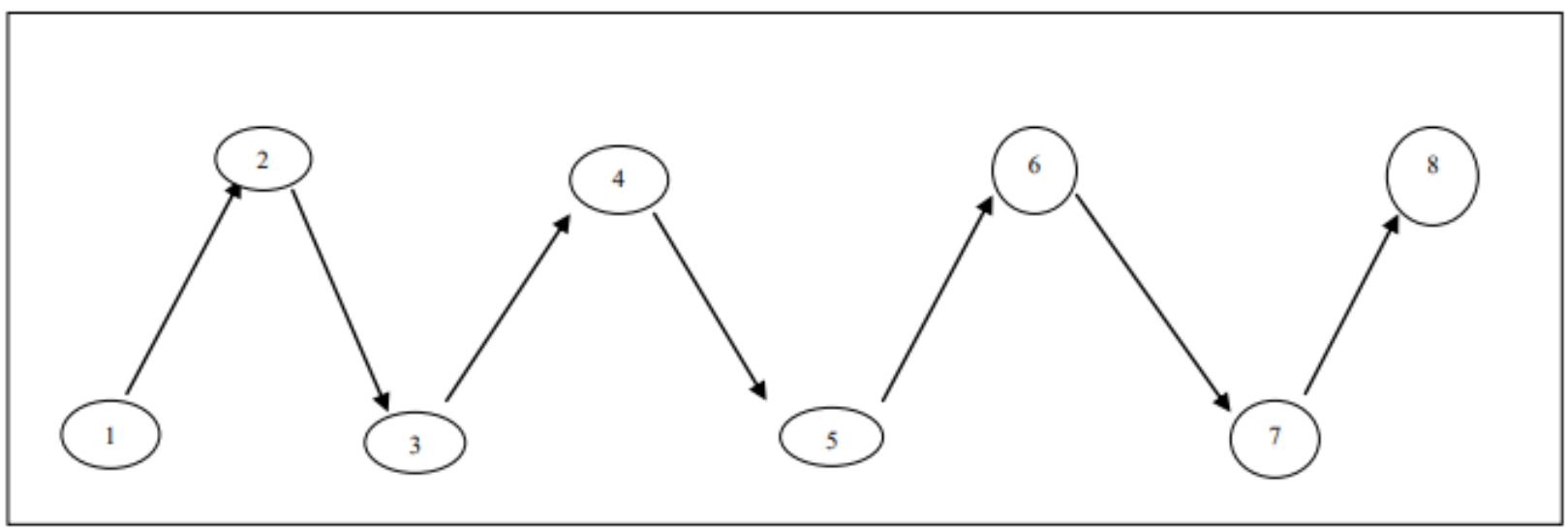

Fonte: Autores (2022).

\subsection{Avaliação microbiológica da cama}

Para avaliação da contagem bacteriana total de mesófilos aeróbios, utilizou-se a técnica de plaqueamento em profundidade (pour plate), conforme descrita por De Silva et al. (2010). Cada amostra foi homogeneizada e retirada 25 g, a seguir, foram adicionadas $225 \mathrm{ml}$ de água peptonada tamponada. A partir dessa diluição $\left(10^{-1}\right)$ foram realizadas diluições decimais seriadas até $10^{-6}$. Alíquotas de $1 \mathrm{~mL}$ de cada diluição foram pipetadas, em duplicata, em placas de Petri estéreis. Posteriormente, cerca de $20 \mathrm{~mL}$ de Agar PCA (Plate Count Agar) fundido foi acrescido e homogeneizado com o inóculo. Após a solidificação do meio, as placas foram incubadas a $37^{\circ} \mathrm{C}$ por $48 \mathrm{~h}$, sendo que todas as colônias foram contadas nas placas que apresentavam entre 30 e 300 colônias. Os resultados foram obtidos após a multiplicação do número médio de colônias presentes em cada duplicada, em que foi realizada a contagem, multiplicado pelo inverso da diluição semeada nas referidas placas. A contagem obtida foi expressa em número de unidades formadoras de colônia por grama de cama (UFC.g $\mathrm{g}^{1}$ ).

\subsection{Avaliação do $\mathrm{pH}$, atividade de água e umidade da cama}

$\mathrm{O}$ pH foi medido por meio do auxílio de peagâmetro digital (Hanna instruments, Barueri, SP, Brasil), em uma solução composta por $20 \%$ de cama e $80 \%$ de água destilada. A atividade de água foi realizada por meio do equipamento LabSwift-aw (Novasina, Zurique, Suíça). As análises de umidade da cama foram executadas de acordo com as técnicas descritas por Silva e Queiroz (2009).

Quadro 1. Cronograma de coleta de amostras para análises microbiológicas, pH, atividade de água (Aw) e umidade.

\begin{tabular}{|l|l|l|l|l|l|l|l|l|}
\hline Parâmetro & Dia 0 & Dia 0 + 6h & Dia 7 & Dia 14 & Dia 21 & Dia 28 & Dia 35 & Dia 42 \\
\hline Microbiológico & & & & & & & & \\
\hline $\mathrm{pH}$ & & & & & & & & \\
\hline Aw & & & & & & & & \\
\hline Umidade & & & & & & & \\
\hline
\end{tabular}

Aw - Atividade de água. Fonte: Autores.

\subsection{Análise estatística}

Todas as variáveis foram submetidas ao teste de normalidade (Shapiro-Wilk). Em seguida, os dados foram submetidos à análise de variância (ANOVA) e ao teste de Tukey, em que se considerou diferença entre grupos quando $\mathrm{P}<0.05$ por meio do software R. 


\section{Resultados}

Constatou-se menor contagem bactéria total seis horas após a aplicação em todas as dosagens do blend de ácidos orgânicos e ligninas sobre a cama ( $\mathrm{P}<0,001$; Figura 2). Aos 14 dias após o alojamento, observou-se um aumento na contagem bacteriana total, no entanto, o aviário com a maior dosagem manteve o ambiente menos contaminado $(\mathrm{P}<0,001)$. Não houve diferença para $\mathrm{pH}$, atividade de água e umidade entre tratamentos e ao longo do tempo (P>0.05; Tabela 2; Figura 3,4 e 5).

Tabela 2 - Análise dos parâmetros de qualidade de cama ao longo do período experimental.

\begin{tabular}{|c|c|c|c|c|c|c|c|c|c|}
\hline \multicolumn{10}{|c|}{ Contagem Bacteriana Total (UFC/g) } \\
\hline Níveis & \multicolumn{2}{|r|}{ Dia 0} & Dia 0 + 6h & \multicolumn{2}{|c|}{ Dia 14} & \multicolumn{2}{|l|}{ Dia 28} & Dia 42 & Valor $\mathbf{P}$ \\
\hline $40 \mathrm{~g} / \mathrm{m}^{2}$ & \multicolumn{2}{|r|}{$1,3 \times 10^{7} \mathrm{a}$} & $2,8 \times 10^{6} \mathrm{~b}$ & \multicolumn{2}{|c|}{$3,7 \times 10^{7} \mathrm{a}$} & \multicolumn{2}{|c|}{$3,2 \times 10^{7} \mathrm{a}$} & $6,3 \times 10^{7} \mathrm{a}$ & $<0,001$ \\
\hline $80 \mathrm{~g} / \mathrm{m}^{2}$ & \multicolumn{2}{|r|}{$8,3 \times 10^{6} \mathrm{a}$} & $9,4 \mathrm{X} 10^{6} \mathrm{~b}$ & \multicolumn{2}{|c|}{$4,8 \times 10^{7} \mathrm{a}$} & \multicolumn{2}{|c|}{$4,1 \times 10^{7} \mathrm{a}$} & $6,9 \times 10^{7} \mathrm{a}$ & $<0,001$ \\
\hline $120 \mathrm{~g} / \mathrm{m}^{2}$ & \multicolumn{2}{|r|}{$2,3 \times 10^{7} \mathrm{a}$} & $1,1 \mathrm{X} 10^{7} \mathrm{~b}$ & \multicolumn{2}{|c|}{$2,1 \times 10^{7} \mathrm{a}$} & \multicolumn{2}{|c|}{$4,2 \times 10^{7} \mathrm{a}$} & $7,9 \times 10^{7} \mathrm{a}$ & $<0,001$ \\
\hline Valor P & \multicolumn{2}{|r|}{0,223} & 0,133 & \multicolumn{2}{|c|}{0,123} & \multicolumn{2}{|l|}{0,192} & \multicolumn{2}{|l|}{0,173} \\
\hline & \multicolumn{9}{|c|}{ pH } \\
\hline Níveis & Od & $0+6 h$ & $7 d$ & 14d & 21d & 28d & 35d & 42d & Valor $\mathbf{P}$ \\
\hline $40 \mathrm{~g} / \mathrm{m}^{2}$ & 8,42 & 8,37 & 8,46 & 8,48 & 8,55 & 8,43 & 8,63 & 8,68 & 0,215 \\
\hline $80 \mathrm{~g} / \mathrm{m}^{2}$ & 8,35 & 8,54 & 8,20 & 8,26 & 8,63 & 8,39 & 8,69 & 8,44 & 0,218 \\
\hline $120 \mathrm{~g} / \mathrm{m}^{2}$ & 8,46 & 8,39 & 8,24 & 8,45 & 8,35 & 8,46 & 8,03 & 8,63 & 0,245 \\
\hline \multirow[t]{2}{*}{ Valor P } & 0,148 & 0,199 & 0,194 & 0,152 & 0,234 & 0,124 & 0,219 & 0,219 & \\
\hline & \multicolumn{9}{|c|}{ Atividade de água (Aw) } \\
\hline Níveis & Od & $0+6 h$ & $7 d$ & 14d & 21d & $28 d$ & $35 d$ & $42 d$ & Valor P \\
\hline $40 \mathrm{~g} / \mathrm{m}^{2}$ & 0,745 & 0,739 & 0,814 & 0,809 & 0,778 & 0,761 & 0,780 & 0,799 & 0,187 \\
\hline $80 \mathrm{~g} / \mathrm{m}^{2}$ & 0,763 & 0,756 & 0,764 & 0,783 & 0,805 & 0,736 & 0,743 & 0,772 & 0,146 \\
\hline $120 \mathrm{~g} / \mathrm{m}^{2}$ & 0,810 & 0,791 & 0,757 & 0,820 & 0,797 & 0,821 & 0,835 & 0,829 & 0,133 \\
\hline \multirow[t]{2}{*}{ Valor P } & 0,135 & 0,254 & 0,124 & 0,160 & 0,178 & 0,105 & 0,114 & 0,136 & \\
\hline & \multicolumn{9}{|c|}{ Umidade (\%) } \\
\hline Níveis & Od & $0+6 h$ & $7 d$ & $14 d$ & 21d & $28 d$ & 35d & $42 d$ & Valor P \\
\hline $40 \mathrm{~g} / \mathrm{m}^{2}$ & 18,61 & 19,64 & 16,37 & 17,06 & 16,99 & 12,27 & 19,27 & 14,36 & 0,094 \\
\hline $80 \mathrm{~g} / \mathrm{m}^{2}$ & 15,40 & 15,85 & 16,96 & 13,00 & 20,12 & 12,67 & 20,52 & 14,04 & 0,093 \\
\hline $120 \mathrm{~g} / \mathrm{m}^{2}$ & 16,66 & 17,12 & 14,44 & 17,22 & 12,07 & 17,06 & 14,35 & 17,48 & 0,135 \\
\hline Valor $\mathbf{P}$ & 0,088 & 0,084 & 0,111 & 0,078 & 0,123 & 0,154 & 0,169 & 0,177 & \\
\hline
\end{tabular}

*Médias seguidas por letras maiúsculas diferentes, na mesma coluna, diferem entre si no comparativo entre tratamentos pelo teste Tukey $\mathrm{P}<0,05$. Médias seguidas por letras minúsculas diferentes, na mesma linha, diferem entre si ao longo do tempo Tukey $\mathrm{P}<0,05$. Fonte: Autores. 
Research, Society and Development, v. 11, n. 3, e31111326501, 2022

(CC BY 4.0) | ISSN 2525-3409 | DOI: http://dx.doi.org/10.33448/rsd-v11i3.26501

Figura 2 - Contagem microbiana total (UFC/g) das camas dos aviários.

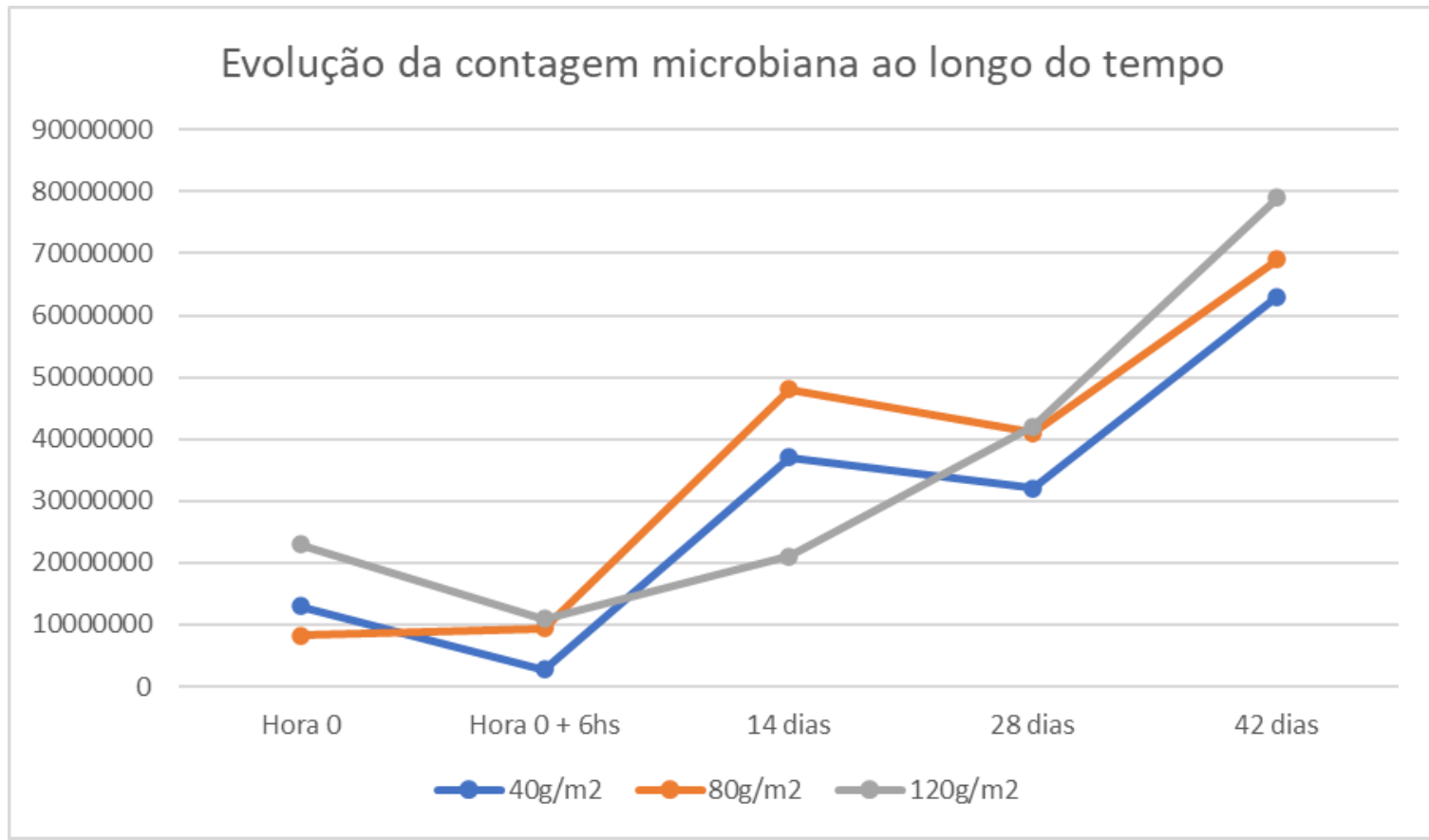

Fonte: Autores (2022).

Figura 3 - pH das camas dos aviários.

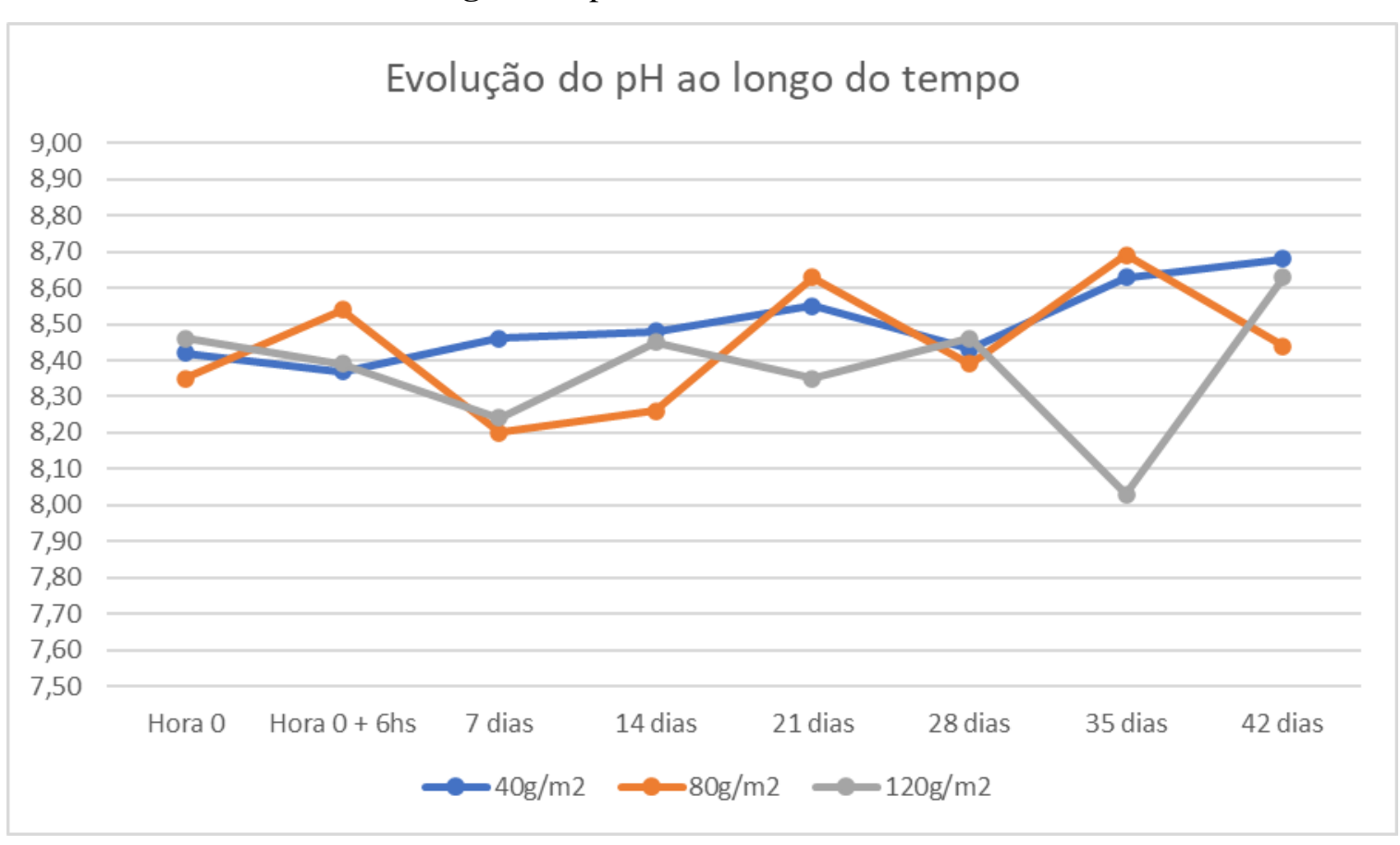

Fonte: Autores (2022). 
Figura 4 - Atividade de água (Aw) das camas dos aviários.

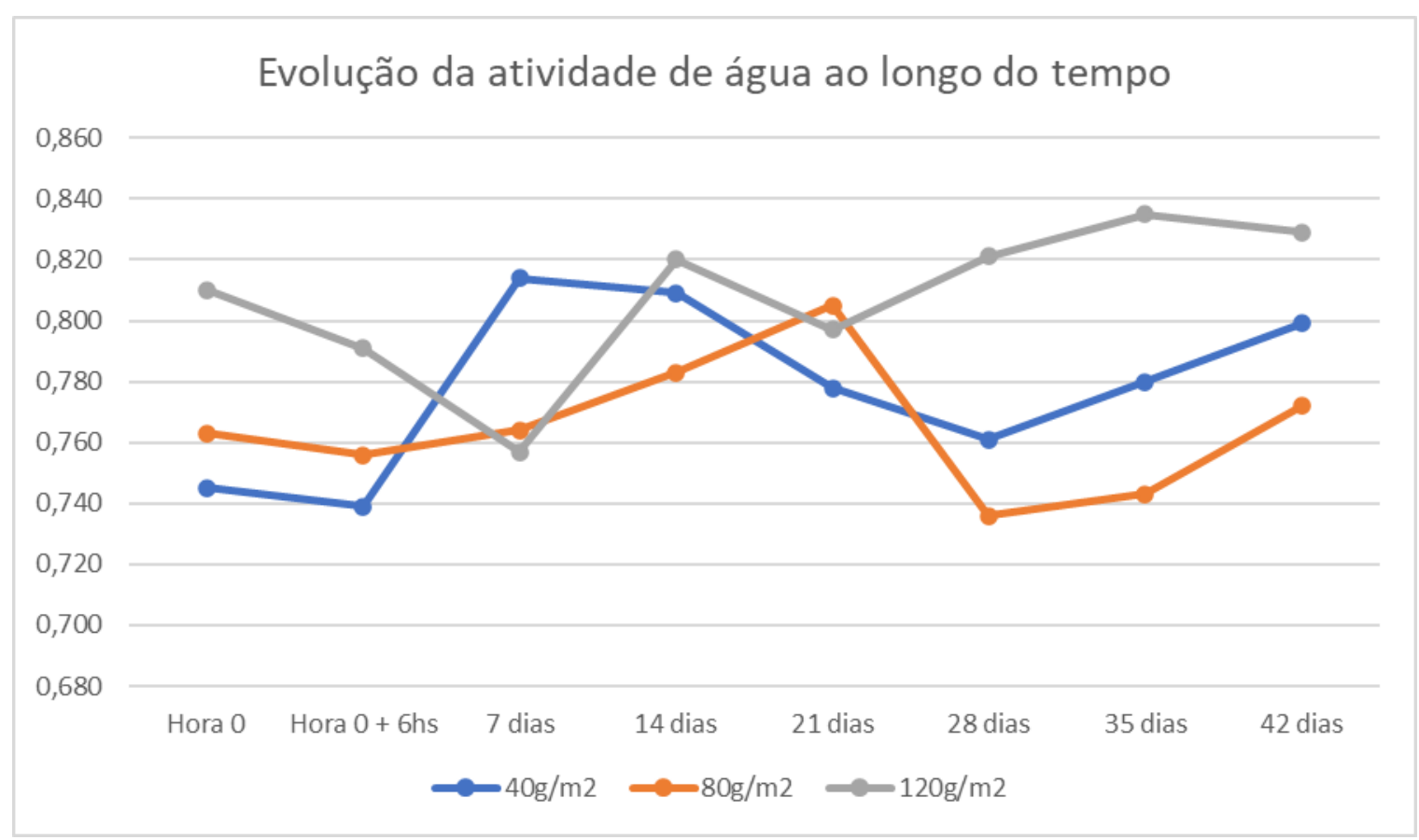

Fonte: Autores (2022).

Figura 5 - Teor de umidade (\%) das camas dos aviários.

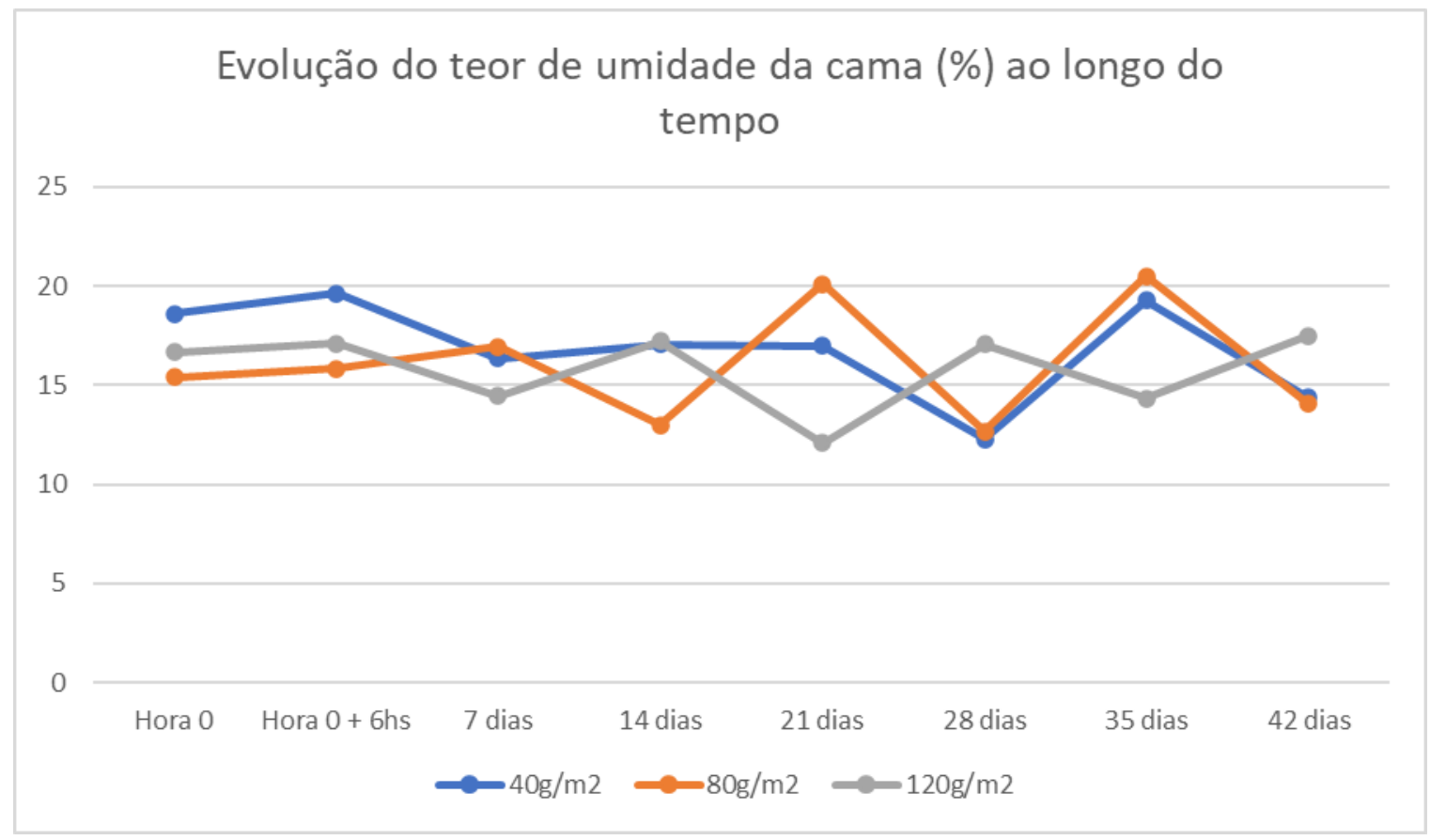

Fonte: Autores (2022).

\section{Discussão}

A contagem microbiana total foi reduzida por meio da adição do produto sobre a cama dos aviários, sendo constatada redução nas amostras seis horas após a aplicação do blend em todas as dosagens testadas. Porém, foi constatado aumento na contagem microbiana total ao longo do tempo de criação dos lotes, em virtude da maior produção de excretas pelas aves e pelo tempo de colonização microbiana na cama em todos os tratamentos avaliados. Assim sendo, a utilização dos acidificantes se 
faz pelo potencial de diminuir o impacto bacteriano da cama, principalmente, no terço inicial de vida das aves, no qual é considerada a fase mais crítica da produção avícola (Gonçalves et al., 2019).

$\mathrm{Na}$ análise da cama aos 14 dias de criação dos lotes, observou-se menor contagem microbiana na cama tratada com $120 \mathrm{~g} / \mathrm{m}^{2}$ do blend, indicando que esta dosagem pode retardar o crescimento microbiano ao longo do período de criação. Porém, a partir dos 28 dias, a adição do blend, em todas as dosagens testadas, não foi suficiente para promover o retardo no crescimento microbiano. Este comportamento pode estar associado a volatilidade dos ácidos, a qual não permite que os mesmos estejam presentes na cama ao longo de todo o período de criação. Silva (2011), relata que devemos nos atentar que a cama utilizada na produção de aves é naturalmente contaminada, com isso, deve-se adotar boas práticas sanitárias com o intuito de reduzir os riscos microbiológicos a níveis compatíveis com o melhor desempenho possível prevenindo-se de potenciais riscos.

Estes resultados sugerem potencial efeito benéfico do produto testado na dosagem de $120 \mathrm{~g} / \mathrm{m}^{2}$. No entanto, aparenta ser necessária uma segunda aplicação, após os 14 dias de criação, e para isso, seria necessário desenvolver uma tecnologia ou forma de aplicação, seja a lanço ou outra forma que não gere problemas de irritabilidade nas aves, pois o aviário estará com as aves alojadas neste momento. Além disso, os lotes não apresentaram histórico de incidência de Salmoneloses, não sendo possível avaliar a influência do mesmo sobre este parâmetro devido à sua ausência. Entretanto, sabe-se que condições ideias de umidade de cama, pH e atividade de água favorecem o crescimento de Salmonella spp, Clostridium spp, Staphylococcus, E. Coli, entre outras agentes patogênicos (Dunlop, 2017). Devido a isso, torna-se importante o monitoramento e controle destes parâmetros, pois são importantes indicativos para o crescimento de microrganismos patogênicos.

Os parâmetros de $\mathrm{pH}$, atividade de água e umidade não sofreram influência dos aditivos aplicados sobre as camas. Porém, durante o período de criação, a região onde o experimento foi conduzido passou por uma forte estiagem, com baixa umidade relativa do ar, o que pode ter influenciado e determinado a ausência do efeito da aplicação do aditivo nas diferentes doses. Visto que todos estes parâmetros de qualidade de cama analisados estiveram dentro dos valores normais preconizados. Tais achados estão de acordo com outras pesquisas realizadas sobre qualidade de cama em aves (Jeffrey, 2001; Dunlop, 2017).

\section{Conclusão}

Os ácidos e ligninas adicionados sobre a cama dos aviários, durante o intervalo entre lotes, possuem efeito mitigador da proliferação microbiana até aos 14 dias de alojamento. Porém, os mesmos não exerceram efeito sobre o $\mathrm{pH}$, atividade de água e teor de umidade nas camas. Portanto, mais estudos são necessários, no qual visam avaliar o efeito de um maior número de aplicações deste produto ao longo do tempo de criação dos lotes.

\section{Referências}

ABPA. (2021). Relatório Anual ABPA 2021. Associação de proteína animal. http://abpa-br.org/wpcontent/uploads/2021/04/ABPA_Relatorio_Anual_2021_web.pdf.

Bogusławska-Tryk, M. Szymeczko, R. Piotrowska, A. Burlikowska, K. Śliżewska, K. (2015). Ileal and cecal microbial population and short-chain fatty acid profile in broiler chickens fed diets supplemented with lignocellulose. Pak Vet J, 35(2), 212-216.

Cobb. (2019). Manual de Manejo de Frango de corte. https://www.cobb-vantress.com/assets/Cobb-Files/df5655a7e9/Broiler-Guide-2019-PORWEB.pdf.

Dai, D. Qiu, K. Zhang, H. -J. Wu, S. -G. Han, Y. -M. Wu, Y.-Y. Qi, G.-H. Wang, J. Organic Acids as Alternatives for Antibiotic Growth Promoters Alter the Intestinal Structure and Microbiota and Improve the Growth Performance in Broilers. Frontiers in Microbiology, 11.

Daí Pra, M. A. Corrêa, E. K. Roll, V. F. Xavier, E. G. Lopes, D. C. N. Lourenço, F. F. Zanusso, J. T. \& Roll, A. P. (2009). Uso de cal virgem para o controle de Salmonella spp. e Clostridium spp. em camas de aviário. Ciênc Rural, 39(4),1189-1194.

De Silva, N. Junqueira, V. C. C. Silveira, N. F. A. Taniwaki, M. H. Santos, R. F. S. \& Gomes, R. A. R. (2010). Manual de métodos de análise microbiológica de alimentos e água. 4 ed. São Paulo: Livraria Varela, 632. 
Research, Society and Development, v. 11, n. 3, e31111326501, 2022

(CC BY 4.0) | ISSN 2525-3409 | DOI: http://dx.doi.org/10.33448/rsd-v11i3.26501

Dunlop, M. W. (2017). Quantifying poultry litter conditions and relationships with odour emissions, PhD thesis, University of New South Wales. Sydney, NSW, Australia. http://www.unsworks.unsw.edu.au/primo_library/libweb/action/dlDisplay.do?

Fiorentin, L. Vieira, N. D. \& Barioni JR. W. (2005). Oral treatment with bacteriophages reduces the concentration of Salmonella Enteritidis PT4 in caecal contents of broilers. Avian pathol, 34 (3), 258-263.

Galli, G. M. Boiago, M. M. Roscamp, E. Muller, L. K. Stefani, L. M. Mendes, R. E. Gris, A. Dilkin, J. D. Oliveira, R. Kolm, M. A. \& Da Silva, A. S. (2021). Gypsum improves broiler litter quality and reduces footpad lesions. Anim Prod Sci, 61(16), 1686-1993.

Gonçalves, N. S. Komiyama, C. M. De Lima, J. de F. P. De Moraes, M. D. G. Savegnago, F. B. Mezzalira Júnior, C. Da Rosa, C. C. B. \& Staub, L. (2019). Qualidade da cama de frango de corte e a alternativa da acidificação como tratamento. Nativa, 7(6), 828-834.

Heitmann, S. Stracke, J. Adler, C. Ahmed, M. F. E. Schulz, J. Büscher, W. Kemper, N. \& Spindler, B. (2020). Effects of a slatted floor on bacteria and physical parameters in litter in broiler houses. Vet Anim Sci, 9, 100115.

Jeffrey, J.S. (2001) Inactivation of bacteria in stacked poultry litter. Davis: University of California 8, (USPEA Final Report).

Ma, J. Wang, J. Mahfuz, S. Long, S. Wu, D. Gao, J. \& Piao, X. (2021). Supplementation of Mixed Organic Acids Improves Growth Performance, Meat Quality, Gut Morphology and Volatile Fatty Acids of Broiler Chicken. Animals, 11(11), 3020.

Polycarpo, G.V. Andretta, I. Kipper M. Cruz-Plycarpo, V.C. Dadalt J.C. Rodrigues P.H.M. \& Albuquerque R. (2017). Meta-analytic study of organic acids as an alternative performance-enhancing feed additive to antibiotics for broiler chickens. Poult Sci, 96(10), 3645-3653.

R Core Team (2013). R: A language and environment for statistical computing. R Foundation for Statistical Computing, Vienna, Áustria. http://www.Rproject.org/.

Röhe, I. Metzger, F. Vahjen, W. Brockmann, G.A. \& Zentek, J. (2020). Effect of Feeding Different Levels of Lignocellulose on Performance, Nutrient Digestibility and Intestinal Microbiota in Slow Growing Broilers. Poult Sci, 99 (10), 5018-5026.

Silva, D.J. \& Queiroz, A.C. (2009). Análise de alimentos: métodos químicos e biológicos. (3a ed.), UFV, 235

Silva, V. S. (2011). Métodos e segurança sanitária na reutilização de cama de aviários. Embrapa Suínos e Aves-Capítulo em livro científico (ALICE). 